\title{
Suicidal Behaviour among Female and Male Commercial Sex Workers; Interpersonal Therapy as A Mode of Intervention
}

\author{
Vaniprabha G. V¹ S. G. Jadhav ${ }^{2}$
}

\section{ABSTRACT}

Suicidal behaviour and Depression among the 100 Female and 100 Male Commercial Sex Workers (CSW'S) and their mode of suicide was studied. Interpersonal therapy was initiated to lower their Depression and Suicidal behaviour. Despite the difference in the suicidal attempts among these population A 8 weeks' therapy and 6 month follow up lowered their Depression and no further suicide attempts. This study explored these factors among this population in Bengaluru, India

Keywords: Commercial sex worker, Depression, Suicidal Behaviour, Interpersonal Therapy,

In India Commercial sex work is widespread, [17]. There are 6 million female sex workers in India, with 35.47 percent of them entering the trade before the age of 18 years[9]. Male prostitution is not a very new concept in India [1]. Men providing sexual services to women or couples in an absolutely professional manner are termed as gigolos who charge money for the services provided [2] Extent of Depression is relevant for suicide and the mode of Suicide in this population.[7] .

CSW's undergo lot of trauma in their lives frequently showing signs of Depression, anxiety and post traumatic stress disorder leading to symptoms of worthlessness, hopelessness, extreme guilt, death wishes and finally attempting suicide.[5]

A low sense of belongingness is the experience that one is alienated from others, not an integral part of a family, circle of friends, or other valued group this research proved that perceived burdensomeness, and social alienation were the important impending factors and there is abundant evidence that this factor is implicated in suicidal behaviour [3,11].

\footnotetext{
${ }^{1}$ Currently Pursuing, Ph.D. at Karnatak University Dharwad

${ }^{2}$ Associate Professor, Dept of Psychology, KCD, Dharwad

*Corresponding Author

(C) 2015 I G Vaniprabha, S Jadav; licensee IJIP. This is an Open Access Research distributed under the terms of the Creative Commons Attribution License (http://creativecommons.org/licenses/by/2.0), which permits unrestricted use, distribution, and reproduction in any Medium, provided the original work is properly cited.
} 


\section{DESIGN}

This longitudinal study was conducted at a Tertiary General hospital, Bangalore, India.

100 Female Commercial Sex Workers and 100 Male Commercial Sex workers both who have begun this CSW activity since 1 year or less were chosen for this study.

\section{HYPOTHESIS}

There will be a difference in the mode of suicide attempts and level of Depression among the two categories of commercial sex workers.

Interpersonal Therapy will help them lower their depression and Suicidal behaviour .

\section{INCLUSION CRITERIA}

- Written consent was taken from all the subjects.

- Women and Men above the age of 18 years up to 25 years

- Women and Men should be engaged in Commercial sex activity

- They should have attempted suicide.

\section{EXCLUSION CRITERIA}

- Women and Men should not have any other physical co-morbidities

- Women and Men with HIV and STD's were ruled out.

\section{METHODOLOGY}

100 Women and 100 Men in sex trade since 1 year or less between the ages of 18 to 25 years were chosen for this study, after a written consent from

Women had completed education up to $10^{\text {th }}$ standard they were from a low to middle socio economic status and majority of them belonged to Hindu religion. While, $80 \%$ of the Men had completed 1th and 5\% had completed $11^{\text {th }}$ std and remaining15\%had finished 12 th std and majority belonged to Muslim religion. To ascertain the number of suicide attempts, mode of suicide and severity of Depression Columbian Suicide History Form (CSHF) and Hamilton Rating scale for Depression (HAM-D) was administered .[4] 
RESULTS

100 Female CSW'S and Male CSW's were identified

Age group was 18 to 25 years

Female CSW's had attempted suicide at least once in the past 1 year and the mode was drowning and consumption of unknown tablets as per (CSHF). TABLE I

Table I, Indicates the Mode of Suicide Attempt among Female CSW's Age 18-25 Years.

\begin{tabular}{|c|l|l|}
\hline No & \multicolumn{1}{|c|}{ SUICIDE ATTEMPTS } & MODE OF SUICIDE \\
\hline 100 Female CSW'S & 1 Attempt & Drowning And Unknown Tablets \\
\hline
\end{tabular}

While, 48 Male CSW's had attempted suicide two times in the past 1 year through the use of poison and insecticides and the remaining 52 had attempted once through Slashing their wrist and hanging as per (CSHF) TABLE II.

Table II, Indicates the Mode of Suicide Attempts and Number of Attempts among Male CSW's Age 18-25.

\begin{tabular}{|l|l|l|}
\hline \multicolumn{1}{|c|}{ No } & \multicolumn{1}{|c|}{ SUICIDE ATTEMPTS } & \multicolumn{1}{c|}{ SUICIDE MODE } \\
\hline 48 Male CSW'S & 2 Attempts & Oral Poison, Insecticide \\
\hline 52 Male CSW'S & 1 Attempt & Hanging, Slashing Wrist \\
\hline
\end{tabular}

\section{PRE INTERPERSONAL THERAPY INTERVENTION ASSESSMENT}

Pre Interpersonal Therapy intervention assessment for Severity of depression was done using HAM-D.

The scores for Female CSW's was significantly higher, the score was 16 and Male CSW's the score were 14.

They were counselled about the use of Anti-Depressants they denied trying it hence an intensive Interpersonal Therapy was done.

\section{INTERPERSONAL THERAPY}

The interpersonal-psychological theory of suicidal behavior (Joiner, 2005) proposes that an individual will not die by suicide unless s/he has both the desire to die by suicide and the ability to do so. What is the desire for suicide, and what are its constituent parts? [11]

In answer to the first question of who desires suicide, the theory asserts that when people hold two specific psychological states in their minds simultaneously, and when they do so for long 
enough, they develop the desire for death. The two psychological states are perceived burdensomeness and $a$ sense of low belongingness or social alienation.[12]

Self-preservation is a powerful enough instinct that few can overcome it by force of will[7]. The few who have developed a fearlessness of pain, injury, and death, which, according to the theory, they acquire through a process of repeatedly experiencing painful and otherwise provocative events. These experiences often include previous self-injury, but can also include other experiences, such as repeated accidental injuries; numerous physical fights; and occupations like physician [8]and front-line soldier in which exposure to pain and injury, either directly or vicariously, is common[10].

Perceived burdensomeness is the view that one's existence burdens family, friends, and/or society. This view produces the idea that "my death will be worth more than my life to family, friends, society, etc." - a view, it is important to emphasize, that represents a potentially fatal misperception. Past research, though not designed to test the interpersonal-psychological theory, nonetheless has documented an association between higher levels of perceived burdensomeness and suicidal ideation. [12]

A low sense of belongingness is the experience that one is alienated from others, not an integral part of a family, circle of friends, or other valued group. As with the research base on perceived burdensomeness, there is abundant evidence that this factor is implicated in suicidal behaviour [16].

The female population showed symptoms of higher levels of perceived burdensomeness and suicidal ideation and male Population showed high Social Alienation. Since the trauma this population is exposed to day in and day out makes them vulnerable to go against the concepts of Self preservation and commit suicide [14].

They were met three times a week and Interpersonal Therapy was initiated each session lasted for 45 minutes for a period of 8 weeks. These techniques were used to lower Depression and suicidal behaviour. A six month follow up showed that there was no suicide attempt[12].

\section{POST INTERVENTION ANALYSIS}

The HAM-D scores post CBT intervention for Female CSW group was 10 and Male CSW group was 9 respectively these were analysed using a simple t test and the values were significant at 0.001 level which indicated that there was a significant improvement in the levels of severity of depression. 
Suicidal Behaviour among Female and Male Commercial Sex Workers; Interpersonal Therapy as A Mode of Intervention

PRE AND POST INTERPERSONAL THERAPY INTERVENTION HAM-D SCORES FOR BOTH THE GROUPS WITH “t” ANALYSIS

Table III, Indicates the Level Of Significance of Pre and Post Intervention Ham-D Scores for Female CSW'S

\begin{tabular}{|l|l|l|}
\hline PRE INTERVENTION & POST INTERVENTION & SIGNIFICANCE \\
\hline 16 & 10 & 0.001 level \\
\hline
\end{tabular}

Table IV, Indicates the Level Of Significance of Pre and Post Intervention Ham-D Scores for Male CSW'S

\begin{tabular}{|l|l|l|}
\hline PRE INTERVENTION & POST INTERVENTION & SIGNIFICANCE \\
\hline 14 & 09 & 0.001 level \\
\hline
\end{tabular}

\section{DISCUSSION}

There was a very strong relationship between the number of years into CSW activity and mode of Suicide.

\section{SUICIDE ATTEMPTS}

Female CSW's had 1 attempt and their mode was drowning or unknown tablet consumption.

In the Male CSW's group 48 people had 2 attempts by oral poisoning or Insecticide and the remaining 52 had 1 attempt by Hanging or slashing the wrist.

Both the groups were cautious not to use burns as a mode of attempt which was significant. During interview, they expressed this concern that if they fail to complete suicide due to burns then their life is scarred permanently as they would not be able to carry out their commercial sex activity being their primary concern.[15].

There was a great deal of perceived burdensomeness and social alienation which was identified in this group [11].

\section{MAJOR FINDINGS}

There was a major difference in the mode of suicide among the two different groups i.e., Female and Male CSW's. Interpersonal therapy[12] was taken up for both the groups and this helped them maintain abstinence and the severity of depression[6] had also lessened with no attempts on life which lasted till a 6 month follow up. 


\section{CONCLUSION}

This study enhanced the hypothesis that there is a strong relationship between the mode of suicide attempt and Depression among female and male commercial sex workers.

HAM-D scores post Therapy had a significant decrease in the scores [4] in both the groups indicating the decrease in the severity of depression.

The female population showed symptoms of higher levels of perceived burdensomeness and suicidal ideation and male Population showed high Social Alienation. Since the trauma this population is exposed to day in and day out makes them vulnerable to go against the concepts of Self preservation and commit suicide.

8 weeks of Interpersonal Therapy helped them to lower their Depression.[11]

A follow up of 6 months duration ensured they had not attempted on life during that period.

Despite the differences in the mode of suicide among the Female and Male categories of Commercial sex workers, the Interpersonal Therapy was effective in lowering depression suggested by no further suicide attempts among both the groups.

\section{LIMITATIONS}

The sample was mainly from the urban areas and those who visited the Outpatient unit of the psychiatry department.

Information revealed during the interview could not be cross verified as there was no other means to do so.

\section{DISCLAIMER}

There was no funding received for this study from any agency.

\section{REFERENCES}

1. A study of knowledge and practices among commercial sex workers registered under jyoti sangh STD clinic, Ahmedabad National Journal of Community Medicine 2010, Vol. 1, Issue 2

2. Biller, O.A. (1977). Suicide related to the assassination of President John F. Kennedy. Suicide and Life Threatening Behavior, 7, 40-44.

3. Boardman, A. P., Grimbaldeston, A. H., Handley, C., Jones, P. W., \& Willmott, S. (1999). The North Staffordshire suicide study: a case-control study of suicide in one health district. Psychological Medicine, 29, 27-33.

4. Brown, G., Beck, A. T., Steer, R., \& Grisham, J. (2000). Risk factors for suicide in psychiatric outpatients: A 20-year prospective study. Journal of Consulting and Clinical Psychology, 68, 371-377. 
5. Chandrasekaran P, Dallabetta G, Loo V, Rao S, Gayle H, Alexander A. Containing HIV/AIDS in India: the unfinished agenda. Lancet Infect Dis. 2006;6:508-521.

6. Conner, K., Britton, P., Sworts, L., \& Joiner, T. (2007). Suicide attempts among individuals with opiate dependence: The critical role of felt belonging. Addictive Behaviors, 32, 13951404.

7. De Catanzaro, D. (1995). Reproductive status, family interactions, and suicidal ideation: Surveys of the general public and high-risk groups. Ethology \& Sociobiology, 16, 385-394.

8. Hawton, K., Clements, A., Sakarovitch, C., Simkin, S., \& Deeks, J.J. (2001). Suicide in doctors: A study of risk according to gender, seniority, and specialty in medical practitioners in England and Wales, 1979-1995. Journal of Epidemiology and Community Health, 55, 296-300.

9. Hosain GM, Chatterjee N, Beliefs, sexual behaviors and preventive practices with respect to HIV/AIDS among commercial sex workers in Daulatdia, Bangladesh, Public Health, 2005; 119:371-81.

10. Joiner, Jr., T. E., Hollar, D., \& Van Orden, K. A. (2006). On Buckeyes, Gators, Super Bowl Sunday, and the Miracle on Ice: "Pulling Together" is associated with lower suicide rates. Journal of Social and Clinical Psychology, 25, 180-196.

11. Joiner, T.E. (2005). Why people die by suicide. Cambridge, MA: Harvard University Press.

12. Joiner, T.E., Conwell, Y., Fitzpatrick, K.K., Witte, T.K., Schmidt, N.B., Berlim, M.T., et al. (2005). Four studies on how past and current suicidality relate even when "everything but the kitchen sink” is covaried. Journal of Abnormal Psychology, 114, 291-303.

13. National AIDS Control Programme, Country Scenario Update Published by Ministry of Health and Family Welfare, National AIDS Control Organization, Government of India, 1991.

14. Patel V, Kirkwood BR, Pednekar S, et al. Gender disadvantage and reproductive health risk factors for common mental disorders in women: a community survey in India. Arch Gen Psychiatry. 2006;63:404-413.

15. Patel V. Commentary: Preventing suicide: need for a life course approach. Int J Epidemiol. 2007;36:1242-1243.

16. Rao, V., I. Gupta, M. Lokshin, and S. Jana. 2003. "Sex Workers and the Cost of Safe Sex: The Compensating Differential for Condom Use Among Calcutta Prostitutes.” Journal of Development Economics 71(2003): 585-603.

17. Shahmanesh M, Wayal S. Targeting commercial sex workers in Goa, India: Time for a strategic rethink? Lancet. 2004;364:1297-1299. 